\title{
Training locally elected representatives to act as change agents to promote egalitarian gender norms: Lessons learned from the Do Kadam Barabari Ki Ore programme-Policy brief
}

\author{
K.G. Santhya \\ Population Council \\ Shireen J. Jejeebhoy
}

Follow this and additional works at: https://knowledgecommons.popcouncil.org/departments_sbsr-pgy

Part of the Civic and Community Engagement Commons, Demography, Population, and Ecology Commons, Domestic and Intimate Partner Violence Commons, Family, Life Course, and Society Commons, and the International Public Health Commons How does access to this work benefit you? Let us know!

\section{Recommended Citation}

Santhya, K.G. and Shireen J. Jejeebhoy. 2017. "Training locally elected representatives to act as change agents to promote egalitarian gender norms: Lessons learned from the Do Kadam Barabari Ki Ore programme-Policy brief." New Delhi: Population Council. 


\section{Introduction}

Community mobilisation has increasingly been recognised as an important strategy to change unequal gender norms and reduce violence against women and girls. In India, locally elected representatives of Panchayati Raj Institutions (PRIs, local self-governance bodies) are among the most promising potential agents of change. As the locally elected representatives of PRIs are tasked with the responsibility of implementing schemes for social justice, protection of women from violence falls directly within its mandate. The potential for building the capacity of these elected representatives and instilling in them a sense of accountability for preventing violence has been poorly utilised.

This policy brief describes an intervention, the Do Kadam Barabari Ki Ore (Two Steps Towards Equality) project, that sought to train locally elected representatives to act as change agents to promote egalitarian gender norms among men and women in their communities, and the effects of exposure to the project among PRI members and men and women from the community. The project was undertaken by the Population Council, together with partners, the Centre for Catalysing Change (C3) and the London School of Hygiene and Tropical Medicine, and with support from UKaid.

\section{Do Kadam Barabari Ki Ore}

The intervention was implemented over a seven-month period in nine villages from two panchayats of Masaurhi Block in Patna district. It comprised a number of components. It began with developing a 14-session curriculum for sensitising PRI members and building their capacity to address violence against women and girls and alcohol abuse ${ }^{1}$ in their communities. Male and female PRI members received training through an initial three-day training workshop followed by fortnightly training sessions based on the curriculum for the entire seven months of the intervention. Aside from these sessions, exposure visits were held for PRI members in order to provide them first-hand information on services and programmes available to support women in distress and those in need of help to address alcohol problems, build the confidence of the PRI members to enable them to impart what they learned in these visits to the community at large, and support them to refer individual cases.

Following their exposure to each training session, PRI representatives, with support from C3 and its local partner, Abhiyan, held community-level sensitisation sessions in their wards to build awareness among community members on issues addressed during the training session that they had attended. Aside from these sessions, PRI representatives were supported to hold community-wide campaigns and such events as street theatre, film shows, and local rallies on ending gender discrimination, violence against women and girls, and domestic violence related to alcohol abuse.

We conducted in-depth interviews with 18 PRI members from villages in which the intervention activities were implemented before launching the intervention and at its conclusion to assess their perceptions about the acceptability and effects of the project on their own attitudes and practices as well as on those of their community members. We used a quasi-experimental design to evaluate the effect of the project among married men and women in the community. Before we launched the intervention, we interviewed a total of 763 married men in the ages 18-54 and 767 married women in the ages 18-49 who were selected both from villages in which the intervention was implemented (intervention villages) and from villages in which the intervention was not implemented (comparison villages). After the intervention was completed, we interviewed a fresh group of 757 married men and 766 married women from the same villages. Additionally, we held in-depth interviews with 10 men and women each who had participated in the baseline survey from intervention villages at two points in time-before launching the intervention (baseline) and after the intervention was over (endline).

${ }_{1}^{1}$ We note that our study preceded the prohibition of alcohol in April 2016.

POPULATION COUNCIL

Ideas. Evidence. Impact.

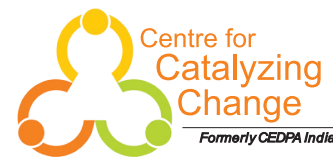

LONDON SCHOOL of HYGIENE \&TROPICAL MEDICINE 


\section{PRI members' participation in the Do Kadam Barabari Ki Ore programme}

The two intervention panchayats included 52 gram panchayat and gram kachehri members, of whom more than half were women. All of these 52 elected representatives attended at least one training session; 79 percent attended more than half of all sessions, 23 percent attended almost all of the 14 fortnightly training sessions, and 79 percent participated in at least one exposure visit. Most PRI representatives reported that this was the very first training programme they had ever attended. As can be seen from the following reports, PRI members responded favourably to the programmes.

Yes, I participated and it was a three-day training programme. We were told about equality between boys and girls, that we should stop alcohol, that there shouldn't be any violence against women, everyone should live in harmony. Yes, I learned new things, like women should make a group and help in stopping alcohol, everyone should live in harmony. [Female, aged 50 , completed Class 2, panchayat representative for 8 years, endline, ID05]

We were taken to the women's police station, the women's helpline, etc. I knew about them before but had never been to any such facility. So I visited these facilities for the first time because of this programme. I was very happy. [Male, aged 43 , completed Class 15, panchayat member for 3 years, endline, ID14]

Figure 1: PRI members' participation in Do Kadam Barabari Ki Ore programme, intervention villages, project monitoring data

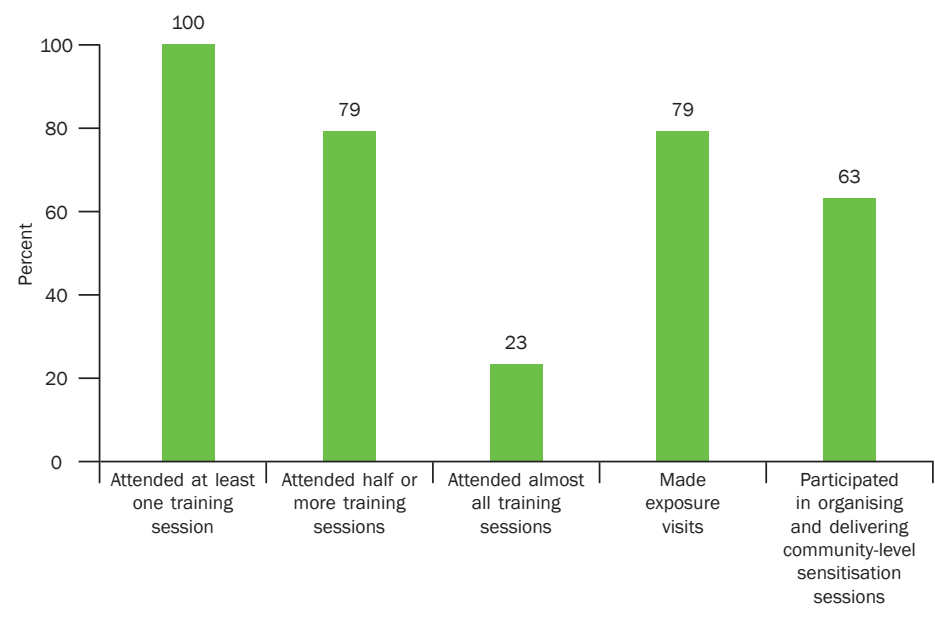

Over three-fifths (63\%) of PRI members participated in organising and delivering community-level sessions. These sessions attracted an audience of, on average, 32 community members. Over the course of the intervention, two meetings of the Mahila Nyay Samiti (Women's Justice Committee) were held in each gram panchayat, in which committee members discussed individual cases and referred them, as appropriate, to other services, such as the Helpline and the Mahila Thana. ${ }^{2}$ A few PRI members suggested that while earlier meetings used to address village development matters, over the previous months, gender equality, marital violence, and alcohol abuse were also discussed. The following responses describe the sessions and meetings.

There is a meeting every month. About what development is taking place in the village, where there is a need for a canal, where a handpump is needed. Since the Do Kadam programme has begun, we also discuss violence against women and how one should behave in marriage. Sometimes 100, 90 people attend, sometimes 50. [Male, age 43, completed Class 12, panchayat member for 8 years, endline, ID12]

Yes, we organised the session, we discussed education, how to be free from alcohol, domestic violence. Both men and women participated, sometimes 20-25, not necessarily the same people. [Male, aged 38, completed Class 12, panchayat representative for 3 years, endline, ID16]

\section{Community members' awareness of and participation in the Do Kadam Barabari Ki Ore programme}

At the time of the endline, 69 percent of men and 61 percent of women residing in intervention villages reported awareness of the Do Kadam programme. More men and women were aware of the street plays than were aware of the sensitisation sessions organised as part of the programme (60\% versus $43 \%$ among men; $48 \%$ versus $44 \%$ among women). Hardly any had heard about the Mahila Nyay Samiti (just 4-5\%) or seen the complaint box (3-4\%), both of which were instituted towards the end of the intervention period.

Two-fifths of men and one-third of women reported having attended at least one village-level sensitisation session or street play (Figure 2). Exposure to these was, however, irregular. While 22-24 percent of men and women indicated that they had attended at least one village-level sensitisation session organised by the Do Kadam programme, just six percent had attended such sessions sometimes or regularly. In addition, 26 percent of women and 35 percent of men had attended street plays organised by the programme. Not a single woman reported that she had lodged a complaint or that she knew someone who had lodged a complaint with the Mahila Nyay Samiti.

\footnotetext{
${ }^{2}$ We note that although the intervention aimed to take steps to revitalise the Social Justice Committee, we experienced challenges in doing so; as an alternative, C3 India supported PRI representatives in establishing a parallel but more informal mechanism, the Mahila Nyay Samiti (Women's Justice Committee) to take on this function towards the end of the intervention period.
} 
Figure 2: Participation in the Do Kadam Barabari Ki Ore intervention, married men and women in intervention villages, endline survey

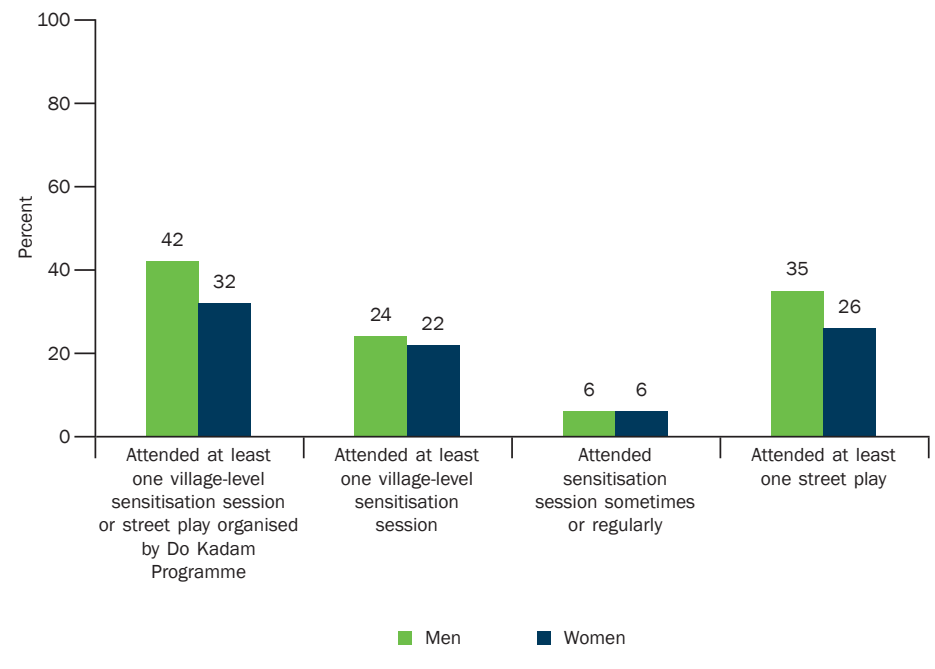

Community members' perceptions about engagement of PRI members on issues related to VAWG and alcohol abuse following the introduction of the Do Kadam Barabari Ki Ore programme

As evident from Figure 3, discourses or meetings on violence against women and girls (VAWG) or alcohol abuse organised by PRI members, as reported by community men and women, increased significantly following the introduction of the Do Kadam programme. Likewise, PRI members' intervention in cases of VAWG or alcohol abuse, as reported by men and women from the community, increased steeply. ${ }^{3}$

Figure 3: Community members' perceptions about engagement of PRI members on issues related to VAWG and alcohol abuse

Men

Women

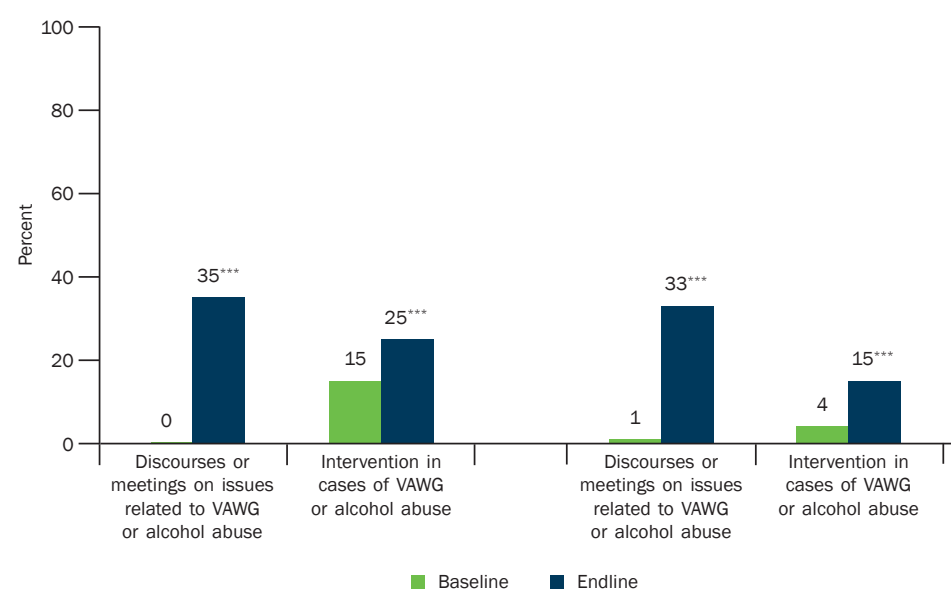

Note: ${ }^{\star * \star}$ indicates that difference between baseline and endline is significant at $p<=0.001$

\footnotetext{
We note that intervention by PRI members refers to intervention for anyone in the village and not necessarily for the respondent.
}

Changes in PRI members' attitudes and behaviours following their participation in the Do Kadam Barabari Ki Ore programme

In in-depth interviews, almost all PRI members reported changes in their own gender role attitudes and attitudes about the acceptability of violence against women; most discussed the need to reduce alcohol abuse in their village and maintain closer, more harmonious and violence-free marital relations.

\section{Gender role attitudes became more egalitarian}

PRI representatives acknowledged that while they had largely adhered to traditional gender role attitudes until exposed to the programme, they were now committed to upholding more egalitarian gender role attitudes and some discussed their commitment to spreading these new attitudes in their communities as well. This commitment is indicated in the two narratives that follow.

Before taking the training, I used to think that whatever was happening was correct but now I feel that it wasn't correct. There is a need for change. A woman should have all the rights at home that a man has. She should also be able to go out of the house by her own choice, she should be able to take decisions related to the home by herself, and she should be able to go out and earn money, She shouldn't require anyone else's permission. For all of this to take place, we need to change the mindsets of men and women, make them more aware, give them information about their rights and duties, and only then will there be equality and a stop to violence against women. [Male, aged 32, completed Class 6, panchayat representative for 3 years, endline, ID18]

\section{Marital violence became less acceptable}

Views about the acceptability of marital violence had also changed, with all PRI members reporting that violence against women should not be tolerated, as can be seen in the following narratives.

Yes there has been a change in this too. Now I think that women are humans and so why do people treat them like animals? We should help them out, we should treat them well and if they ever do make a mistake then we should talk and explain things to them lovingly. In my opinion, talking to one's wife in a loud voice is also a form of violence, and beating her is an even worse offence. [Male, aged 43, completed Class 12, panchayat representative for 8 years, endline, ID12]

Yes, I have clearly understood that violence against any woman should not happen under any circumstances. And that if we see such violence in our community, we should make them understand that they should never do this, that they torture more when they are drunk, and that if a husband doesn't drink alcohol he will commit less physical and mental violence. [Female, aged 46, completed Class 8 , panchayat member for 8 years, endline, ID06] 


\section{Marital relations became more egalitarian and caring} than earlier

PRI representatives, notably male representatives, reported moreover that their relations with their spouse had improved in many ways as a result of the Do Kadam programme exposure. While narratives must be interpreted keeping in mind likely social desirability bias, male PRI representatives identified a host of changes in their marital life, aside from reduced alcohol use and marital violence. They reported that they had stopped emotionally abusing their wife, now spoke with their wife 'lovingly', spent more time with their wife and children, participated in household chores, and acknowledged their wife's agency. We note, however, that female representatives, except one, reported no change in the nature of their marital relations.

Yes there has been an effect on my relationship with my wife too. Now I talk to her lovingly. Compared to before, I give her more respect, I talk to her with respect, and even if she makes a mistake, I don't get angry with her like I used to do before the training. After taking the training, I am more aware of both her rights and of my rights and duties. I have started spending more time with my children, and started behaving well with everyone. I have started helping out more in the house. All in all I now know better what is wrong and what is right, and started behaving better at home and in society. [Male, aged 43 , completed Class 12 , panchayat representative for 8 years, endline, ID12]

Yes there has been a change in our relationship. Compared to before, I talk to her more nicely and lovingly.... I no longer get angry with her or shout at her or speak in a loud tone. Now I live more harmoniously, I spend time with my family, I help my children with their schoolwork, I help my wife out with housework. I know that it is also my responsibility to carry out these chores, so I look after the animals, go to the market, help my wife out in cleaning the house. [Male, aged 43, completed Class 15, panchayat representative for 3 years, endline, ID14]

\section{Intervention in cases of VAWG increased and in cases of alcohol abuse remained challenging}

Narratives suggest that prior to the Do Kadam programme, hardly any PRI representative reported that they had intervened in cases of marital violence: several reported that marital violence was a personal matter and women preferred to remain silent about it, as is evident in the following reports. By the time of the endline in-depth interview, a few PRI representatives reported that they had intervened in cases of violence in which the women had approached them for help. They reported that the problem had been resolved at the level of the panchayat, and that there was no need to approach the police or helpline. Action taken by the panchayat to stop violence against women is described in the following narratives.
Yes, the panchayat intervenes when such matters come to its notice and we speak with both sides to resolve the matter. The panchayat scares and threatens that the offender will be sent to the police. Until now, the cases which have come up like these have been resolved at the panchayat level. The police have never been required, but in the future if the police's help is ever required, it will surely be sought. So far the need has never arisen to go to the helpline or the short-stay home. If their help is ever needed, we will surely go to them as well. Until now people have accepted the decision of the panchayat and resolved the matter in the village itself. [Male, aged 43, completed Class 10, panchayat representative for 8 years, endline, ID12]

There has been a lot of awareness among women through your programme, which is why they have come. Twenty women may have come regarding this issue in the year. I solved their problems through the law or the panchayat and helped them. There is a woman in my ward, RD. Her husband used to hit and abuse her, so we called him and explained. Now they live together nicely. We put social pressure on her husband which is why he doesn't beat or abuse her any more. Yes, now if any woman has experienced violence, then her family and husband are called and we punish them financially or physically. We call them, scold them and make them understand. [Male, aged 43, completed Class 15, panchayat representative for 3 years, endline, ID14]

While PRI representatives, particularly male representatives reported taking actions to address alcohol abuse, including counselling those abusing alcohol and organising protests to curb the sale of alcohol, they acknowledged obstacles in doing so, including political interference when PRI representatives tried to reduce the sale of alcohol, on the one hand, and community members' own reluctance to stop the practice on the other.

\section{Changes in community members' awareness, attitudes, and practices related to VAWG}

Findings indicate that the programme had a mixed effect in changing community members' awareness, attitudes and practices related to VAWG.

\section{Raising awareness of violence-related laws and services for women in distress}

Although the intervention had no effect on raising married men's or women's knowledge about the Domestic Violence (DV) Act, including penalties for violating it, it contributed significantly to enhancing men's and especially women's awareness about services available for women in distress, such as short-stay homes and helplines (Figure 4). Specifically, awareness of support services among men increased by 15 points in intervention arm (23\% at baseline to $38 \%$ at endline) compared to a six-point increase in 
Figure 4: Effect of exposure to the Do Kadam programme on awareness of the Domestic Violence Act and services for women in distress

Awareness of the DV Act

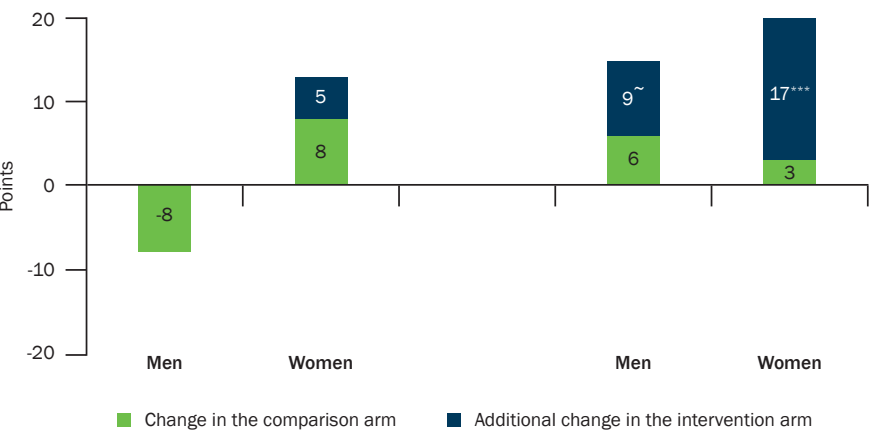

Note: and ${ }^{* * *}$ indicates that the effect of exposure to the Do Kadam programme is significant at $p<=0.10$ and $p<=0.001$, respectively.

comparison arm (21\% to $27 \%)$; among women, it increased by 20 points in intervention arm ( $7 \%$ to $27 \%)$ compared to a three-point increase in comparison arm (5\% to $7 \%$ ).

\section{Reversing discriminatory gender role attitudes and behaviours}

Exposure to the Do Kadam programme did not affect gender role attitudes and attitudes about the acceptability of VAWG. Traditional gender norms, as measured by attitudes towards gender roles and violence against women, remained strong and virtually unchanged in both arms in the endline survey.

Neither men's controlling behaviours nor men's perpetration and women's experience of violence within marriage was affected by exposure to the intervention.

\section{Reducing men's alcohol abuse}

The intervention resulted in a reduction in alcohol abuse among men in the intervention arm, as measured by women's reports of the frequency of their husband's alcohol use, and in their husband's display of drunkenness (Figure 5). While similar proportions of women in comparison arm reported that their husband consumed alcohol once a week or more frequently at baseline and endline (49\% and 51\%), a somewhat smaller proportion so reported at endline than baseline in intervention arm (44\% and 41\%). The percentage of women who reported that they had witnessed their husband drunk at least once in the week declined more steeply in the intervention arm (38\% to $18 \%$ ) than in the comparison arm (42\% to $30 \%)$.

Our findings have demonstrated that, as a result of the intervention, locally elected representatives experienced vast changes in knowledge, attitudes and practices, but changes
Figure 5: Effect of exposure to the Do Kadam programme on husband's alcohol consumption as reported by women

Husband consumed alcohol at least once a week

Witnessed husband drunk at least once a week

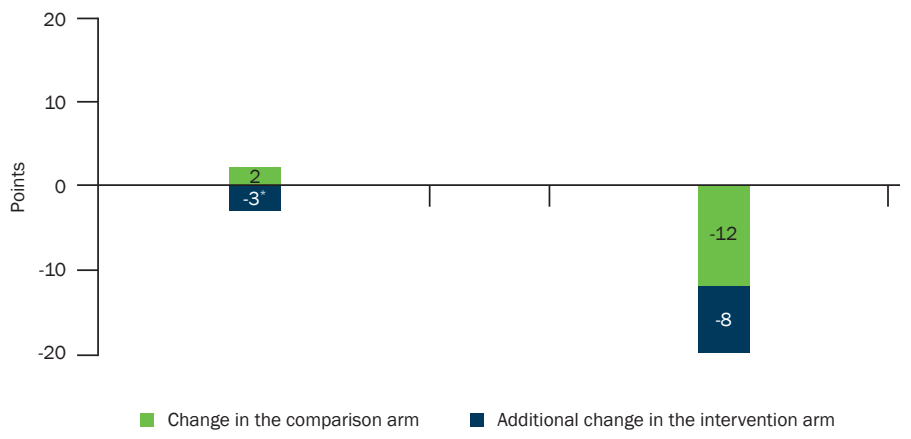

Note: * indicates that the effect of exposure to the Do Kadam programme is significant at $p<=0.05$.

experienced by community members were more limited, restricted to awareness of available services and a decline in men's alcohol abuse.

\section{Recommendations}

The Do Kadam Barabari Ki Ore programme was designed to work within the existing community leadership structure, that is, locally elected representatives, to foster social change. Such a programme was envisaged to ensure community ownership and sustainability. Findings suggest the intervention was promising, and our experience suggests the following recommendations.

\section{Recognise that training PRI members to act as change agents requires sustained efforts}

Our findings have highlighted that PRI representatives themselves hold traditional attitudes, are not necessarily sensitive to the need to change such practices as alcohol abuse and violence against women, and lack the leadership skills necessary to mobilise communities. Indeed, strengthening their capacity to promote social change requires a strong PRI capacity-building phase, accompanied by a strong demonstration phase in which NGOs conduct events and meetings and show locally elected representatives both how to organise a meeting and how to convey messages, and intervene confidently in case of violations. Finally, a transitional mentorship phase is needed, in which the organisation and conducting of events are taken over by PRI representatives themselves, with minimal or no external involvement. While this was the model the Do Kadam programme implemented through $\mathrm{C} 3$ and Abhiyan, we recognise that this three-phased approach is likely to be more time consuming than the seven months of activities conducted under the Do Kadam programme. 
Integrate a module on gender and violence against women in the larger PRI curriculum

Given that deep-rooted gender stereotypical norms underpin several social issues that PRI representatives are entrusted to address, and given the findings from this study that exposing PRI representatives to a gender transformative curriculum can help them to adopt gender egalitarian norms, it is important and timely to integrate a module on gender and violence against women in the larger PRI curriculum.

\section{Take steps to ensure more regular exposure}

The finding that exposure to the intervention eventscommunity-level sensitisation sessions and street playswas irregular, calls for measures to ensure community members' regular participation in the programme. Female study participants who did not attend the programme argued that the location of the event was unsuitable for them or that their husband or family member had denied them permission to attend. Male and female study participants cited competing demands on their time. And finally, not all community members were aware of the programme and the events it organised. Efforts need to be made to better understand and accommodate reasons for poor attendance. PRI representatives may need to reach all community members in their homes, inform them about the intervention, share with them a schedule of events and services that PRI representatives can provide, and convey to them the legitimacy of the programme. If women's hesitation to attend the programme is linked to the presence of men who also attend the programme, separate events may need to be organised for women. Further, given that household chores and other time commitments inhibited many from attending the programme regularly, the programme would need to be more flexible in setting session timings to accommodate these constraints.

\section{Consider a sub-group focus}

In the current programme, events, meetings, and street plays were conducted for the community at large, and messages conveyed were general. It is possible that general messages are more difficult to internalise and adapt to one's own situation; organisers may thus prefer to hold meetings addressing specific groups of community members: men, women, and the young, those assembled at places where liquor is available, those in school, and so on.

\section{Acknowledgements}

The authors would like to gratefully acknowledge insightful comments that Ann Blanc, Mamta Kohli and Nel Druce made on earlier versions of this brief; Komal Saxena helped in the design and production of this brief. The authors also gratefully acknowledge the financial support provided by the UK Department for International Development (DFID).

This brief has been developed based on the following publication: Jejeebhoy, S. J., A. J. Francis Zavier, K. G. Santhya et al. 2017. Modifying behaviours and notions of masculinity: Effect of a programme led by locally elected representatives.

New Delhi: Population Council.

Suggested citation: K. G. Santhya and S. J. Jejeebhoy. 2017. Training locally elected representatives to act as change agents to promote egalitarian gender norms: Lessons learned from the Do Kadam Barabari Ki Ore programme, Policy Brief. New Delhi: Population Council.

\section{Population Council}

Zone 5A, Ground Floor

India Habitat Centre, Lodi Road

New Delhi, India 110003

Phone: +91-11-2464 2901

Email: info.india@popcouncil.org

The study has been funded by UK aid from the UK Government; however the views expressed do not necessarily reflect the UK Government's official policies.

\section{POPULATION COUNCIL \\ Ideas. Evidence. Impact.}

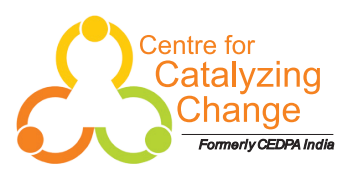

LONDON SCHOOL of HYGIENE \&TROPICAI MEDICINE

The Population Council conducts research and delivers solutions that improve lives around the world. Big ideas supported by evidence: It's our model for global change. www.popcouncil.org 